\title{
TECHNOLOGY AND APPLICATION OF ANTI-GRAFFITI COATING SYSTEMS FOR ROLLING STOCK
}

\author{
Norbert RADEK ${ }^{1}$, Jacek PIETRASZEK², Łukasz PASIECZYNSKI ${ }^{3}$ \\ ${ }^{1}$ Kielce University of Technology, Centre for Laser Technologies of Metals, Kielce, Poland, EU, \\ norrad@tu.kielce.pl \\ ${ }^{2}$ Cracow University of Technology, Institute of Applied Informatics, Cracow, Poland, EU, \\ jacek.pietraszek@mech.pk.edu.pl
}

${ }^{3}$ Firma Handlowa Barwa Jaroslaw Czajkowski, Kielce, Poland, EU, Ipasieczynski@barwa.kielce.pl https://doi.org/10.37904/metal.2019.909

\begin{abstract}
The article describes the technology and application of anti-graffiti coating systems for rolling stock, i.e. coatings resistant to devastation by graffiti-vandals and easy to be renovated later. Paint systems for rolling stock must fulfill mechanical and qualitative properties to longer maintenance protective and decorative properties on the vehicle. Graffiti spray paints should be treated as dangerous substances for coatings because they contain various solvents and other substances that might soften or migrate into protective coating and cause delamination of the coating system and finally lead to shortening durability of the coating surface. Surface free energy is of interest in the field of coating technologies and cleaning procedures, because it is a factor which affects such surface properties and interfacial interactions as adhesion, adsorption and wetting. The contact angle of a liquid on a solid surface is a measure of a free surface energy so the study of wettability and free surface energy is of great practical interest in industrial processes, especially for paints with special properties like anti-graffiti for rolling stock industry. This paper presents results of the investigation on the free surface energy for the anti-graffiti BO100-AGR coating developed in laboratory of Barwa Company. The system consists of high solid corrosion protection primer, putty, filler, basecoat and anti-graffiti clearcoat. The research was based on anticorrosion coatings system with transparent layer with reduced adhesion of each subsequent types of contamination.
\end{abstract}

Keywords: Anti-graffiti coatings, surface free energy, wettability, rolling stock, rail

\section{INTRODUCTION}

By applying new engineering materials or protective coatings, it is possible to improve the functional properties of machine parts so that they are resistant to corrosion, abrasion and erosion, and possess high fatigue strength. The new materials, for instance, alloy steels, are usually costly, which is undesirable, because the higher the cost of the material, the higher the price of a finished product. However, if an element is to be subjected to high loads, then strength rather than cost is a primary factor. Applying protective coatings to machine parts is economically justifiable if the wear is local or if the coating material is expected to display properties different from those of the substrate. Most surface layers are technological surface layers (TSLs) they are produced before objects are used. Functional surface layers (FSLs), on the other hand, are applied during maintenance [1-3] so they are of interest in the field of protection against vandalism.

Currently, anti-graffiti coating systems for rolling stock are experiencing high development dynamics, which have different properties [4]. Graffiti paints, that are difficult to remove, require the use of more aggressive materials, which increase the possibility of mechanical or chemical damage of the coating system and consequently reduce the thickness of the protective coating or remove it completely. In addition, aggressive chemicals removers are dangerous to the users and environment [5].

The article presents the comparative tests results of selected properties of anti-graffiti paint system for rolling stock industry. 


\section{MATERIALS}

Coatings was applied with a SATA spray gun on S355 carbon steel, before the application the surface of steel was polished with 80-grit sandpaper. Coating system consisting of the following layers: anti-corrosion epoxy primer, putty, filler, basecoat and anti-graffiti clearcoat BO100-AGR. Each layer is applied and dried in accordance with the requirements of the technological cards. The prepared samples were conditioned at $23^{\circ} \mathrm{C}$ and $50 \%$ humidity for minimum 14 days in order to perform tests on dry coating.

\section{RESULTS OF INVESTIGATIONS AND DISCUSSION}

\subsection{Microstructure}

A microstructure analysis was conducted for anti-graffiti coating systems using the JEOL JSM-7100F scanning electron microscope with field emission and the Hirox KH-8700 light microscope.
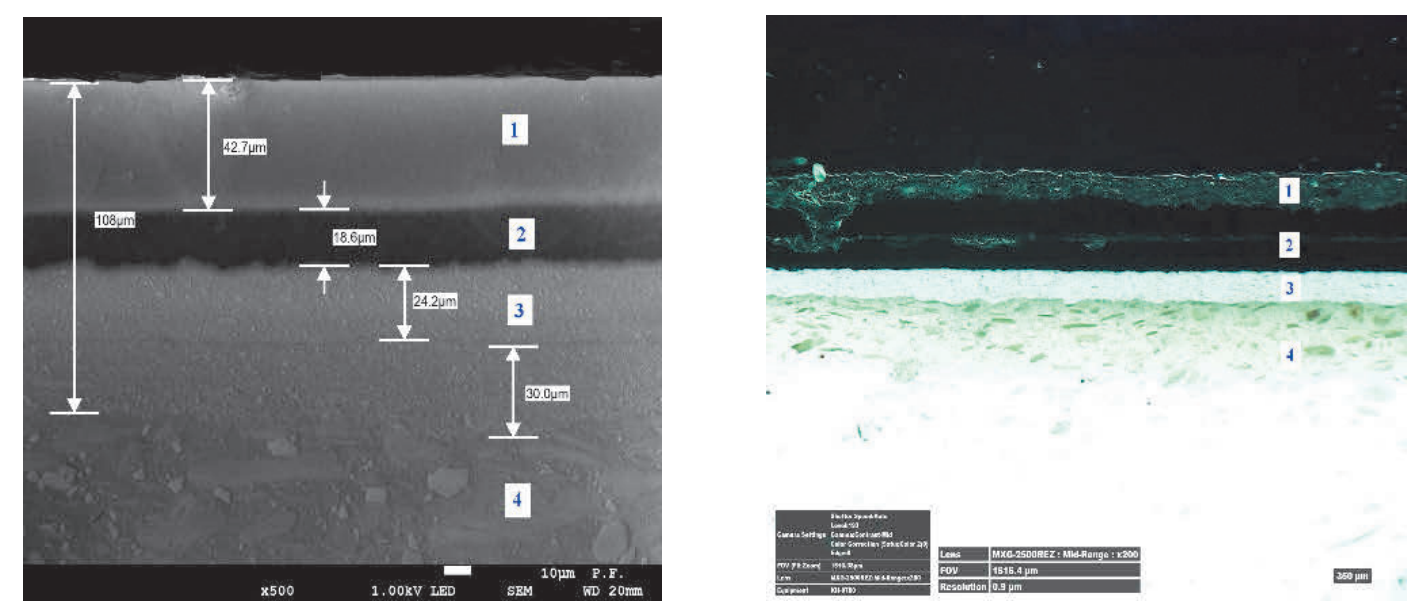

Figure 1 SEM (left) and LM (right) micrographs of the polished cross-section throug a anti-graffiti BO100-AGR coating system on S355 carbon steel substrate: 1- anti-graffiti layer, 2 - base layer, 3 - undercoat layer, 4 - putt

The thickness of the obtained coating systems was from approx. 2350 to approx. $2450 \mu \mathrm{m}$. There are clear boundaries between the individual layers (Figure 1). Figure 1 shows the clear boundary between the varnish layers and the putty. Also the varnish layers are free of pores and microcracks.

\subsection{Measurement of contact angle and free surface energy}

One of the most commonly used methods of determining the contact angle of a material [6] is a method based on the geometry of the droplet (Figure 2). The surface of the droplet is most often in the shape of a circular arc, and then the contact angle is calculated from the measurement of the height $h$ and the radius of the contact surface of the drop $r$. The height of the circular arc is given by $h=R(1-\cos \Theta)$ and the surface contact radius $r=R \sin \Theta$. From these relationships we get a equation (1):

$\Theta=\frac{2 h}{r}$

where:

$\mathrm{h}$ - height of circular arc,

$r$ - the radius of the contact surface of the drop. 
The value of free surface energy of construction materials is determined indirectly by measuring the contact angles of selected measuring fluids. Distilled water and diododomethane (DIM) are used to measure the contact angle. The stereoscopic microscope with the camera and the MicroScan v1.3 software were used for droplet observation and contact angle measurement. The following values of free surface energy constants of the measuring fluids and their polar and dispersion components were assumed: $\gamma_{\mathrm{w}}=72.8\left[\mathrm{~mJ} / \mathrm{m}^{2}\right], \gamma^{\mathrm{p}}=51.0$ $\left[\mathrm{mJ} / \mathrm{m}^{2}\right], \gamma^{d}{ }_{w}=21.8\left[\mathrm{~mJ} / \mathrm{m}^{2}\right], \gamma_{d}=50.8\left[\mathrm{~mJ} / \mathrm{m}^{2}\right], \gamma_{d}^{p_{d}}=2.3\left[\mathrm{~mJ} / \mathrm{m}^{2}\right], \gamma_{d}^{d}=48.5\left[\mathrm{~mJ} / \mathrm{m}^{2}\right]$. The measuring liquid was applied to the test surface with a $5 \mu$ l constant volume micropipette.

Free surface energy (FSE) values were determined by measuring the contact angle. FSE estimation was done at least six times for each surface. Table 1 summarizes the averaged wetting angle and free surface energy measurements of the BO100-AGR anti-graffiti coating systems. Analyzing the obtained results, we can observe high repeatability of the measurements, as evidenced by small values of standard deviations (Table 1).

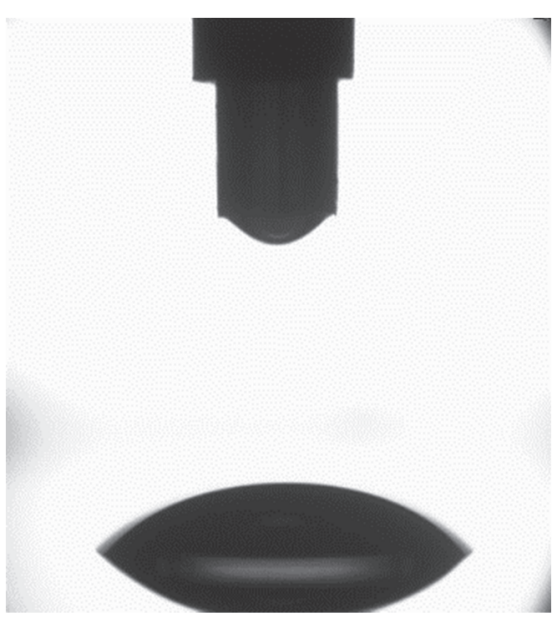

a) b)

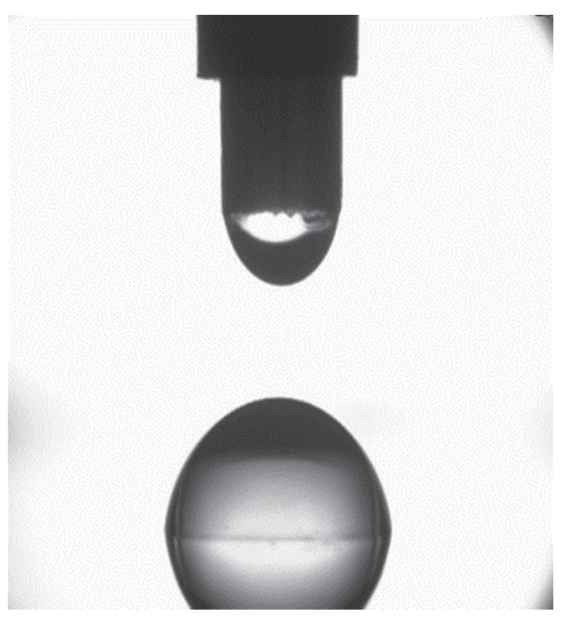

Figure 2 View of measurement of the contact angle of diododomethane (a) and of distilled water (b)

Table 1 Results of contact angle measurements and free surface energy of BO100-AGR anti-graffiti coating systems

\begin{tabular}{|c|c|c|c|c|c|}
\hline $\begin{array}{c}\text { Measuring series } \\
\text { number }\end{array}$ & $\begin{array}{c}\text { Average angle } \\
\text { water }\end{array}$ & $\begin{array}{c}\text { Average angle } \\
\text { DIM }\end{array}$ & $\begin{array}{c}\mathrm{E}_{\mathrm{p}} \\
\left(\mathrm{mJ} / \mathrm{m}^{2}\right)\end{array}$ & $\begin{array}{c}\gamma^{\mathrm{d}} \\
\left(\mathrm{mJ}^{2} / \mathrm{m}^{2}\right)\end{array}$ & $\begin{array}{c}\gamma^{\mathrm{p}} \\
\left(\mathrm{mJ} / \mathrm{m}^{2}\right)\end{array}$ \\
\hline 1 & 78.4 & 40.2 & 49.2 & 40.1 & 9.1 \\
\hline 2 & 80.3 & 40.0 & 48.5 & 40.3 & 8.3 \\
\hline 3 & 80.9 & 40.5 & 48.0 & 39.9 & 8.1 \\
\hline 4 & 83.6 & 39.7 & 47.2 & 40.3 & 6.9 \\
\hline 5 & 79.8 & 41.1 & 48.3 & 39.7 & 8.6 \\
\hline 6 & 80.8 & 41.4 & 47.7 & 39.5 & 8.2 \\
\hline arithmetic average & 80.63 & 40.48 & 48.15 & 39.97 & 8.20 \\
\hline standard deviation & 1.71 & 0.66 & 0.69 & 0.33 & 0.73 \\
\hline
\end{tabular}

One of the most commonly used methods for determining free surface energy is the Owens-Wendt method in which it is assumed that the free surface energy is the sum of two components, dispersion and polar:

$\gamma_{s}=\gamma_{s}^{d}+\gamma_{s}^{p}$ 
where:

$Y^{d} s$ - dispersion component of free surface energy,

$Y^{p} s$ - polar component of free surface energy.

\subsection{Measurement of surface geometric structure}

Measurements of surface geometric structure were carried out at the Laboratory of Computer Measurements of Geometric Quantities of the Kielce University of Technology. The surface geometric structure (SGS) substantially influences many processes that occur in the outer layer. A lot of publications deal with the measurement methods and the assessment of surface roughness and waviness [7-9]. Tests were performed using a Talysurf $\mathrm{CCl}$ optical profilometer using the coherent correlation interferometry method, enabling a resolution of $0.01 \mathrm{~nm}$ with a $\mathrm{z}$ axis resolution. The measurement result is recorded in a matrix of $1024 \times 1024$ measuring points using the $\times 10$ lens, giving a measured area of $1.65 \mathrm{~mm} \times 1.65 \mathrm{~mm}$ and a horizontal resolution of $1.65 \mu \mathrm{m} \times 1.65 \mu \mathrm{m}$. Ten measurements were made on samples of anti-graffiti and S355 steel, allowing averaging of the results. The obtained images of surface stereometry and their analysis using the software TalyMap Platinium allowed to evaluate the geometrical structure of the examined surfaces.

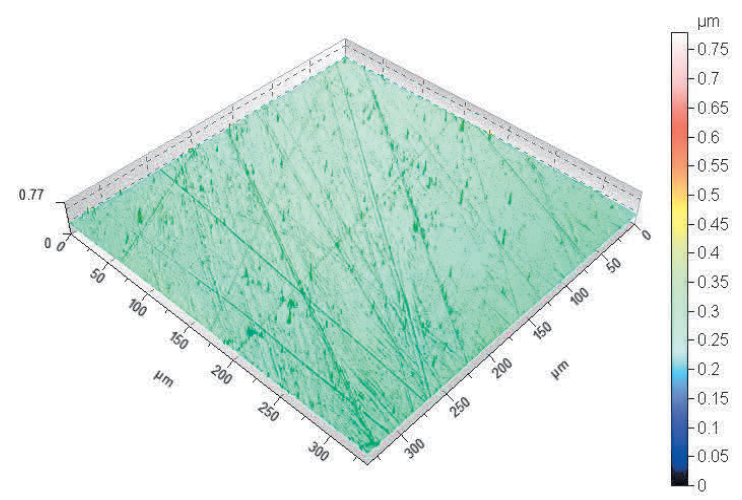

Figure 3 Isometric view of the surface roughness of the anti-graffiti BO100-AGR coating system

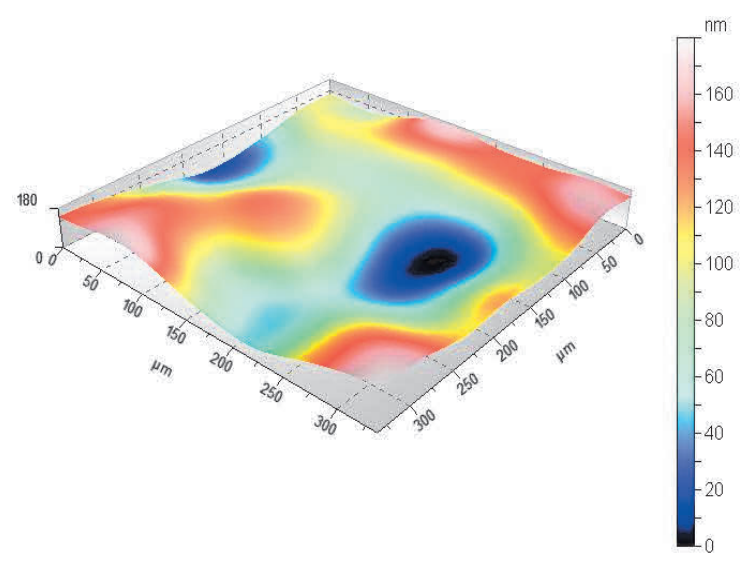

Figure 4 Isometric view of the waviness surface of the anti-graffiti BO100-AGR coating system

Figure 3 shows a sample isometric roughness of the surface of the anti-graffiti BO-100AGR coating system, while Figure 4 shows the isometric image of the wavy surface of the coating system. Table 2 summarizes the most important SGS parameters of the tested anti-graffiti coating systems. The tested anti-graffiti coating systems had averaged mean arithmetic surface roughness deviations from the average surface area $\mathrm{Sa}=6.6 \div 26.9 \mathrm{~nm}$. Samples of S355 steel sanded with P80 grain sandpaper on which coatings were applied had $\mathrm{Sa}=1234.5 \div 1863.2 \mathrm{~nm}$. Parameter $\mathrm{Sa}$ is the basic amplitude parameter for quantifying the state of the 
surface being analyzed. A similar trend in the measurement of anti-graffiti and S355 coating systems was observed for the quadratic surface roughness Sq, which has a strong correlation with the Sa parameter. As a result of coating application, the surface roughness was significantly reduced.

Table 2 Averaged parameters of the surface geometric structure of anti-graffiti BO-100AGR coating system

\begin{tabular}{|c|c|}
\hline SGS parameters & B0100-AGR \\
\hline Sq $(\mathrm{nm})$ & 11.8 \\
\hline Ssk & 6.90 \\
\hline Sku & 155.9 \\
\hline Sp $(n m)$ & 501.9 \\
\hline Sv $(n m)$ & 277.8 \\
\hline Sz $(n m)$ & 779.6 \\
\hline Sa $(n m)$ & 16.8 \\
\hline
\end{tabular}

\section{CONCLUSION}

- $\quad$ Analyzing the microstructure, it can be concluded that the thickness of anti-graffiti coating systems is in the range of $2300 \div 2400 \mu \mathrm{m}$. In addition, paint systems are free of pores and microcracks.

- $\quad$ The BO100-AGR is characterized by good anti-adhesive properties and this is related to the roughness of the topcoat. The BO100-AGR anti-adhesie properties can be significant in potential applications on rail vehicles.

- The high values of the slope coefficient of the surface of the Sku (kurtosis) indicate the low dispersion of the ordinate surfaces. The positive values of the asymmetry coefficient of the surface Ssk (skewness) show that making faces with a smooth surface without deep crack.

The obtained results may be useful for users of installations exposed to devastation and thus they are of great economical interest [10-12], which should be included in the decision-making rules [13]. Regardless, obtained results may be useful in other coatings developments [14-18] and this problem create a true challange for a light microscopy [19] and 3D image analysis methods [20,21]. Recognized analytical problems related to microstructures may be also interested in other similar investigations [22-26].

\section{REFERENCES}

[1] KOTNAROWSKA, D. Analysis of polyurethane top-coat destruction influenceon erosion kinetics of polyurethaneepoxy coating system. Eksploatacja i Niezawodność - Maintenance and Reliability. 2019. vol. 21, pp. 103-114.

[2] MARIAPPAN, T., KAMBLE A. and NAIK S. M. An investigation of primer adhesion and topcoat compatibility on the waterborne intumescent coating to structural steel. Progress in Organic Coatings. 2019. vol. 131, pp. 371-377.

[3] HAAS K. H., AMBERG-SCHWAB, S. and ROSE, K. Functionalized coating materials based on inorganic-organic polymers. Thin Solid Films. 1999. vol. 351, pp. 198-203.

[4] RADEK, N., PASIECZYŃSKI, Ł., PIETRASZEK, J. and BRONǦEK, J. Analysis of the surface geometric structure of the anti-graffiti coating systems intended for rolling stock. Mechanik. 2019. no. 2, pp. 124-127.

[5] PASIECZYŃSKI, Ł., RADEK, N., KŁONICA, M., KAMIŃSKI, J. and ŚWIDERSKI, J. Properties of BO100-AGR clearcoat anti-graffiti coating systems used in the railway industry. Materials Research Proceedings. 2018. vol. 5, pp. 225-230.

[6] RUDAWSKA, A. and JACNIACKA, E. Analysis for determining surface free energy uncertainty by the OwenWendt method. International Journal of Adhesion \& Adhesives. 2009. vol. 29, pp. 451-457.

[7] MILLER, T., ADAMCZAK, S., ŚWIDERSKI, J., WIECZOROWSKI, M., ŁĘTOCHA, A. and GAPIŃSKI, B. Influence of temperature gradient on surface texture measurements with the use of profilometry. Bulletin of the Polish Academy of Sciences. 2017. vol. 65, pp. 53-61. 
[8] PIETRASZEK, J., RADEK, N. and BARTKOWIAK, K. Advanced statistical refinement of surface layer's discretization in the case of electro-spark deposited carbide-ceramic coatings modified by a laser beam. Solid State Phenomena. 2013. vol. 197, pp. 198-202.

[9] RADEK, N., WAJS, E. and LUCHKA, M. The WC-Co electrospark alloying coatings modified by laser treatment. Powder Metallurgy and Metal Ceramics. 2008. vol. 47, no. 3-4, pp. 197-201.

[10] BROZOVA, S., INGALDI, M. and SPERLIN, I. Economical aspects of high-temperature heating utilization for industrial waste treatment. In METAL 2013: 22th Int. Conf. on Metallurgy and Materials. Ostrava: TANGER 2013, pp. $1735-1739$.

[11] DZIUBA S.T. and INGALDI M. Segregation and recycling of packaging waste by individual consumers in Poland. In $15^{\text {th }}$ Int. Multidisciplinary Scientific Geoconference (SGEM). Albena: Bulgarian Acad. Sci. 2015, vol. III, pp.545552.

[12] DZIUBA, S.T., INGALDI, M. and KADLUBEK, M. Use of quality management tools for evaluation of the products' quality in global economy. In $16^{\text {th }}$ Int. Scientific Conf. on Globalization and its Socio-Economic Consequences. Rajecke Teplice, Slovakia: Univ. Zilina, 2016, pp. 425-432.

[13] PACANA, A., PASTERNAK-MALICKA, M., ZAWADA, M. and RADON-CHOLEWA, A. Decision support in the production of packaging films by cost-quality analysis. Przemysł Chemiczny. 2016. vol. 95, pp. 1042-1044.

[14] SKONECZNY, W. and BARA, M. Aluminium oxide composite layers obtained by the electrochemical method in the presence of graphite. Materials Science-Poland. 2007. vol. 25, pp. 1053-1062.

[15] BARA, M., SKONECZNY, W. and HAJDUGA, M. Ceramic-graphite surface layers obtained by the duplex method on an aluminium alloy substrate. Chemical and Process Engineering. 2009. vol. 30, pp. 431-442.

[16] KMITA, T. and BARA, M. Surface oxide layers with an increased carbon content for applications in oil-less tribological systems. Chemical and Process Engineering. 2012. vol. 33, pp. 479-486.

[17] BARA, M., KMITA, T. and KORZEKWA, J. Microstructure and properties of composite coatings obtained on aluminium alloys. Arch. Metall. Mater. 2016. vol. 61, pp. 1107-1112.

[18] SKONECZNY, W., NIEDZWIEDZ, M. and BARA, M. The effect of production parameters of oxide layers on their nanostructure, nanomorphology, and surface free energy. Applied Sciences-Basel. 2018. vol. 8, art. 2251.

[19] SZCZOTOK, A. and ROSKOSZ, S. New possibilities of light microscopy research resulting from digital recording of images. Materials Science-Poland. 2005. vol. 23, pp. 559-565.

[20] GADEK-MOSZCZAK, A. and WOJNAR, L. Objective, quantitative and automatic x-ray image analysis of the bone regenerate in the ilizarov method. In ECS10: The 10th European Congress of Stereology and Image Analysis. Milan: ISS, 2009, pp.453-458.

[21] KORZEKWA, J., GADEK-MOSZCZAK, A. and ZUBKO, M. Influence of the size of nanoparticles on the microstructure of oxide coatings. Materials Science. 2018. vol. 53, pp. 709-716.

[22] SZCZOTOK, A. and SOZANSKA, M. A comparison of grain quantitative evaluation performed with standard method of imaging with light microscopy and EBSD analysis. Praktische Metallographie-Practical Metallography. 2009. vol. 46, pp. 454-468.

[23] SZCZOTOK, A. RICHTER, J. and CWAJNA, J. Stereological characterization of gamma prim phase precipitation in CMSX-6 monocrystalline nickel-base superalloy. Materials Characterization. 2009. vol. 60, pp. 1114-1119.

[24] KLIMECKA-TATAR, D., PAWLOWSKA, G. and RADOMSKA, K. The effect of Nd12Fe77Co5B6 powder electroless biencapsulation method on atmospheric corrosion of polymer bonded magnetic material. In METAL 2014: 23rd Int. Conf. on Metallurgy and Materials. Ostrava: TANGER, pp. 985-990.

[25] INGALDI, M. and DZIUBA S.T. Modernity evaluation of the machines used during production process of metal products. In METAL 2015: 24 $4^{\text {th }}$ Int. Conf. on Metallurgy and Materials. Ostrava: TANGER 2015, pp. 1908-1914.

[26] SYGUT, P., KLIMECKA-TATAR, D. and BORKOWSKI, S. Theoretical analysis of the influence of longitudinal stress changes on band dimensions during continuous rolling process. Arch. Metall. Mater. 2016. vol. 61, pp.183188. 